\title{
вмJ Global Health What we have learnt (so far) about deliberative dialogue for evidence- based policymaking in West Africa
}

\author{
Valéry Ridde, ${ }^{1,2,3}$ Christian Dagenais ${ }^{4}$
}

To cite: Ridde V, Dagenais C. What we have learnt (so far) about deliberative dialogue for evidence-based policymaking in West Africa. BMJ Glob Health 2017;2:e000432. doi:10.1136/ bmjgh-2017-000432

Handling editor Seye Abimbola

Received 1 June 2017

Accepted 10 November 2017

\section{(a) CrossMark}

${ }^{1}$ School of Public Health, Universite de Montreal, Montreal, Quebec, Canada ${ }^{2}$ University of Montreal Public Health Research Institute (IRSPUM), Montreal, Canada ${ }^{3} \mathrm{RRD}$ (French Institute For Research on sustainable Development), CEPED (IRDUniversité Paris Descartes), Universités Paris Sorbonne Cités, ERL INSERM SAGESUD,

Paris, France

${ }^{4}$ Department of Psychology, University of Montreal, Montreal, Canada

\section{Correspondence to} Professor Valéry Ridde, IRD (French Institute For Research on sustainable Development), CEPED (IRD-Université Paris Descartes);

valery.ridde@umontreal.ca

\section{ABSTRACT}

Policy decisions do not always take into account research results, and there is still little research being conducted on interventions that promote their use, particularly in Africa. To promote the use of research evidence in Africa, deliberative dialogue workshops are increasingly recommended as a means to establish evidenceinformed dialogue among multiple stakeholders engaged in policy decision-making. In this paper, we reflect on our experiences of conducting national workshops in six African countries, and we propose operational recommendations for those wishing to organise deliberative dialogue. Our reflective and cross-sectional analysis of six national deliberative dialogue workshops in which we participated shows there are many specific challenges that should be taken into account when organising such encounters. In conclusion, we offer operational recommendations, drawn from our experience, to guide the preparation and conduct of deliberative workshops.

\section{BACKGROUND}

What it is now commonly referred to as the "science of using science" has taught us that political decisions do not always take into account research evidence. Only the most naïve scientist would expect their work to automatically influence policy-makers without first devoting sustained efforts to transforming, adapting and communicating the results. ${ }^{2}$ Discussions on the relationship between scholars and politicians go back a long way, certainly as far as Weber, at least. ${ }^{3}$ However, the well-informed citizen (who is sometimes also a researcher ${ }^{4}$ ), in Africa or elsewhere, would prefer that policies and projects not be based solely on decision-makers' personal ideas and experiences, electoral issues, researchers' career strategies or even just the opinions of people with the means to express them. ${ }^{5}$

In the health sector, and especially in the specific context of West Africa, this question is particularly relevant, in that very little research is available on interventions fostering research evidence use. ${ }^{6}$ For

\section{Key questions}

What is already known about this topic?

- Political decisions do not always take into account research evidence.

- In West Africa, very little research is available on interventions to foster research evidence use.

- Deliberative dialogue is a promising mechanism to promote research evidence use.

What are the new findings?

- There are many challenges to be tackled when organising deliberative dialogue.

- Results highlight the importance of taking into account the specific contexts of West Africa to maximise the effectiveness of deliberative dialogue.

\section{Recommendations for policy}

- Drawing from our experiences of conducting national workshops in six African countries, we propose operational recommendations for organising effective deliberative dialogue.

example, we know access to health information has been crucial in efforts to reduce maternal mortality in high-income countries, ${ }^{7}$ whereas there is little such research evidence for West African countries. Decision-makers are influenced by numerous forces: institutional constraints, interest group pressures, personal convictions and values, external factors such as economic recession or elections, and lastly...research data. ${ }^{8}$ Likewise, there are numerous factors that determine whether and how research evidence is taken into account in decision-making, such as decision-makers' opinions about research utility, their skill in interpreting and using research evidence and whether there is a supportive context for its use. ${ }^{1011}$ Our systematic scoping review showed that most of these factors are the same in low-income countries, and we have identified them in our work in West Africa, in particular. ${ }^{12} 13$ Specific combinations of these factors are likely to determine the use of research evidence, depending on 
the type of information to be transferred, the type of use intended, the type of users and the contexts in which they find themselves.

One strategy that is increasingly advocated to encourage research evidence use in Africa is the deliberative dialogue workshop. ${ }^{14}$ While there are numerous definitions of deliberative dialogue, ${ }^{15} 16$ the strategy described in this paper refers to workshops that 'allow research evidence to be considered together with the views, experiences and tacit knowledge of those who will be involved in, or affected by, future decisions about a high priority issue. ${ }^{17}$ Although there is still relatively little research evidence on the effectiveness of deliberative dialogue for encouraging research evidence use, a scoping review presently under way within our team shows that, out of 25 studies measuring its effects on research evidence use, 21 presented positive findings. ${ }^{18}$ These include the acquisition of new knowledge, the intention to use the research evidence, and concrete actions aimed at implementing recommendations emerging from deliberative dialogues. These concrete actions vary from setting up a national network to promote minority rights, to creating a knowledge transfer platform or producing documentary films. These results are consistent with our recent experiences in organising, facilitating and evaluating deliberative dialogues.

In this paper, we reflect on our experiences in six West African countries (Benin, Burkina Faso, Côte d'Ivoire, Mali, Niger, Senegal) and offer operational recommendations to guide those wishing to organise this type of deliberative dialogue. We focus on issues relating to national level workshops rather than on local issues or smaller projects (on this subject, see one example of our experiences in West Africa, published elsewhere ${ }^{19}$ ).

\section{THE DECISION-MAKING CONTEXT IN FRANCOPHONE WEST AFRICA}

The setting for the organisation of these deliberative dialogues, and for our reflections, is a particular West African context (notably French-speaking), the outlines of which are set out below.

In most of these countries, international donors play a very important role and wield great influence, given state budgets' reliance on assistance, particularly in the health sector. ${ }^{20}$ This influence, however, is not solely financial, and has a bearing on solutions proposed..$^{21}$ Sometimes international aid agencies prefer to sell turnkey solutions rather than to propose and discuss several options for addressing a locally identified problem..$^{22}$ In Benin, for example, donors divided the country into zones to test different forms of performance-based financing, all of them funded by the donors themselves. ${ }^{23}$ However, as shown in the case of universal health coverage in Africa, 'government ownership and donors' influence can successfully coexist ${ }^{24}$ Like every country in the world, but perhaps more exacerbated, West African public administrations are often very politicised, with senior officials being aligned with the parties in power. These 'experts' change with every election, resulting in loss of institutional memory regarding decisions taken, and even sometimes of expertise, although this might occasionally be retrieved by international organisations. It is also a context in which the presence of scientists and the production of research evidence is often very limited..$^{25}$ Moreover, given the very weak infrastructure and funding in the research sector, researchers often morph into consultants with limited availability, producing commissioned reports and not always inclined to apply the necessary critical reflection. ${ }^{26}$

\section{A reflective analysis}

Based on our experience over recent years of participating in and organising six national deliberative dialogues, where new health policies are formulated and implementation is discussed, we believe these contextual challenges have an impact on their organisation. The characteristics of these six deliberative dialogues are presented in table 1 . The two authors of this article were participants and/or members of the technical organisation team for all these dialogues.

The method we apply in this paper, therefore, is one of reflective analysis. ${ }^{27}$ Evidence to support this analysis is drawn from: (1) our active participation in and contribution to these workshops since 2010; (2) workshop reports, policy briefs, evaluations and analyses written by the organisers or ourselves (table 1); and (3) our own reflexive thinking to produce this paper. To improve the fidelity of the workshop descriptions and strengthen the credibility of our reflective analysis, we shared the first draft of this paper with some colleagues who participated in the deliberative dialogues.

Reflective and cross-sectional analyses of these different deliberative dialogues reveal many specific challenges that need to be taken into account in their organisation.

\section{Challenges involved in national deliberative dialogues}

Most often, there is insufficient time available to plan and prepare deliberative dialogues. Teams swing into action sometimes just a few weeks prior to the date, and lastminute changes in strategy are often required. Yet for these workshops to be effective, the key stakeholders, including high-level decision-makers, must actually be available and present, motivated, and prepared. In Niger, for example, the conference was planned 6 months ahead and, despite complications, the health minister became involved 3 months beforehand. ${ }^{28}$ This high-level commitment even enabled the launch of the conference to be carried out by the prime minister. In Benin, Senegal and Côte d'Ivoire, the day before the deliberative dialogue, the organisers still did not know whether the health minister would be present at the opening (as it turned out, they were). As such, organisers need to be responsive, as this situation is more often the norm than the exception. Setting up a cross-sectoral preparation committee might also be useful, as well as occasional subcommittees-communication, scientific, logistical, 


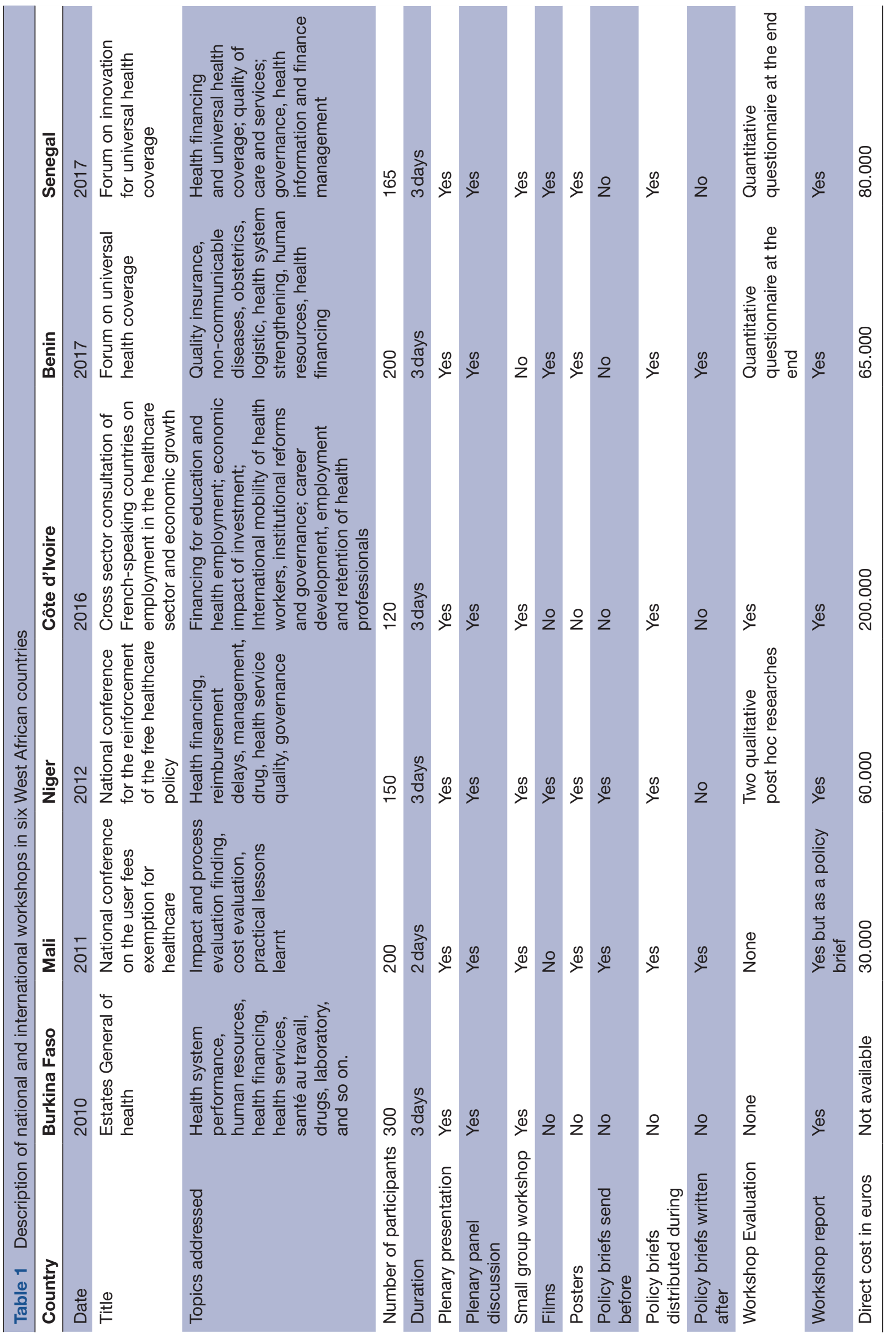

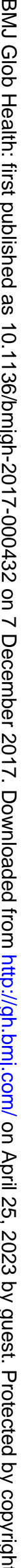


and so on. Caution is advised, however, as these can be costly in terms of time and per diem, which are common practice in this context. ${ }^{29}$ The presence of senior decision-makers is essential, otherwise decision-making is impossible or postponed, thereby undermining the effectiveness of the process. In Benin, for example, the financial resources director from the Ministry of Health never made an appearance during the 3-day workshop, and the human resources director stayed only for his own presentation. At the final plenary session, one attendee asked from the floor what were the commitments and objectives of the State. Nobody wished to respond to this question; the panel chair referred it to the assistant secretary general of the Ministry of Health, who passed it on to the chief of staff of that same ministry, who said he would respond later-all this, even though the president of the Republic's representative to the Global Fund to Fight AIDS, Tuberculosis and Malaria was present but did not take the opportunity to speak. In Côte d'Ivoire, the workshop (organised by the governments of Côte d'Ivoire and of France, in partnership with WHO, the International Labour Organisation and other UN agencies) had scheduled the participation of the ministers for health, economy and social protection of 20 West African countries. None of these ministers, with the exception of those present at the opening and closing conferences, was able to attend. We suggest, therefore, that while efforts must be made to bring to these deliberative dialogues the technical experts in the matter to be discussed, it is absolutely essential that the presence of politicians and decision-makers be arranged beforehand and guaranteed, so that the deliberative dialogue does not become just one more workshop whose effectiveness is questionable. ${ }^{30}$

It is essential to allow time for preparation for several reasons-the main one being that it facilitates the production of summary documents intended for decision-makers and participants (such as policy briefs ${ }^{31}$ ). These notes can be based on research evidence and evaluation findings, both of which are based on rigorous methods, and on reflective analyses of experiences and tacit knowledge. These may be the result of knowledge capitalisation processes, disseminated through reports or policy briefs, as we organised in Senegal in 2017 to provide the actors in the field with data that they could present in the deliberative dialogue, ${ }^{32}$ or as we did for seven West African countries in 2011. ${ }^{33}$ They can also be shared in the form of short documentary films presented at the workshops to vary the types of media and to use images to convey the reality of tacit knowledge, as was done in Benin, Niger and Senegal. Most often, however, tacit knowledge is mobilised during discussions in deliberative dialogues when those workshops have been sufficiently well organised to 'loosen people's tongues', as was said in Niger. ${ }^{28}$ Exchanging knowledge is essential, and when documents are carefully prepared for both style and content and distributed before the deliberative dialogue (as we did in Niger), the chances of their being read are much improved. If documents are prepared
Box 1 The key points of an effective policy brief

Succint: two to four pages, 1500 words.

- Understandable: clear and simple language, and providing a well explained argument.

- Professional, not academic: the audience is NOT interested in the analysis procedure.

- Accessible: facilitate the ease of use by subdividing the text using clear titles.

- Paragraphs: short.

- Sentences: simple.

- Promotional: catch the eye using colours, logos, photos, illustrative quotes and so on.

- Recommendations: feasible, strongly supported by the data/ evidence.

beforehand but only handed out during the workshop, specific time must be allotted for participants to read them, otherwise they will return to their routines without having examined them. In Benin and Senegal, for example, these briefs were prepared just 2 weeks before the workshop, which was far too short a time to polish, test and edit them. In Senegal, due to a logistical problem, policy briefs were distributed at the end of the first day in paper versions and again on the last day in a USB key (flash drive) along with all other documents shared during the workshop (presentation, poster, film, policy brief, knowledge capitalisation report, etc). In Mali, a final note summarising all debates was produced in the days following the national deliberative dialogue, with the main organisers critically involved in its content, and then widely distributed and shared on a website. In Côte d'Ivoire, a series of 16 policy briefs (some over 10 pages long!) were prepared-but only in English. For this simple reason, they were not sent to the participants from the 23 French-speaking countries. Such notes must be reviewed by experts in the field and then, if possible, presented in exploratory form to potential recipients to ensure that the language, style, key messages and operational recommendations are appropriate. Box 1 presents some characteristics of effective policy briefs, according to multiple sources ${ }^{34-36}$ and our own decade of experiences.

The workshop should encourage deliberation and exchange rather than clashes and the reinforcement of preconceived notions. Lengthy presentations should be avoided, while discussion panels and participative and dynamic group work are to be encouraged. In Niger and Senegal, groups worked on different topics (medicine, finance, governance, etc) for over 3 hours, and their deliberations resulted in proposals of concrete recommendations. In Benin, on the other hand, no such work was planned, and the selection of recommendations was limited to a small group of people who arguably may not have been representative of all the participants. If presentations are made, the speakers must absolutely be trained before the deliberative dialogue to avoid overladen slides, illegible charts, useless statistics, scientific jargon incomprehensible to those without a solid 
research background, and so on. This occurred in almost all the workshops we attended. Yet adapting the language to different target audiences is a crucial condition for promoting research evidence use.

Time management is a major issue in these deliberative dialogues, where everyone wants to have their say and where it is often difficult, for sociocultural reasons, to cut people off. At the deliberative dialogues in Benin and Senegal, the decision was taken to start playing some background music a few seconds before the end of the allotted presentation time, then letting the music grow louder until it blotted out the speaker's voice. This was very effective, except for one situation in Senegal, where a panel was chaired by a person known for his long diatribes, whose official position and symbolic power prevented anyone from cutting him off. As such, the selection of moderators is a subtle play of pragmatism, for logistical purposes, and politics, for decision-making. Deliberative dialogue must not be understood as an end in itself but as an integrated means in an extended process designed to encourage decision-making. The organisation is not the end of it; once that is well in hand, it is important to look quickly ahead to the next stage. A monitoring committee could be set up with a mandate to produce a road map for implementing the recommendations. This committee should be as inclusive as the workshop participants and must have the means at its disposal to hold meetings and make progress. In Niger, Senegal and Benin, such a committee was set up, whereas in Mali nothing was done and, to our knowledge, the workshop discussions were never followed up. In Niger, the monitoring committee convened over a period of months, but then the disappearance of its members for reasons of corruption and political changes made it difficult to continue. ${ }^{28}$ In Côte d'Ivoire, a report was prepared by WHO following the consultation and sent to the High Commission, for which it was intended. However, it was impossible to trace what impact the consultation results may have had in the final report of this Commission. ${ }^{37}$

To foster consensual decision-making during these deliberative dialogues, they should be as inclusive and participative as possible. Every voice must be heard, and national decision-makers should be at the heart of the process and decisions, in a context where international aid organisations are very influential. In Mali, given that several studies were in progress on the subject of free healthcare policies funded by various donors, the deliberative dialogue workshop was able to involve them all in its organisation and funding, as well as to give them a platform at which to speak during the 2 days. In Benin, however, this approach was more difficult, and the challenges associated with coordinating donors in field interventions were reflected in the lack of diversity in the participants. Furthermore, during their communications, several speakers repeatedly thanked the development project that had led the organisation of the event, and whose logo was very conspicuous, thereby giving more prominence to the project than planned. It is important, however, to take into account balances of power. In particular, when selecting invitees and allotting speaking time, the organising committee should take time to analyse the actors, stakeholders and issues of power around the subject under discussion. There are numerous tools and approaches available for this purpose. ${ }^{38}{ }^{39}$ The value given to a university professor's words can easily outweigh that given to a community manager of a mutual health insurance programme and can influence the debate and the resulting decisions. In Burkina Faso, for example, a gynaecology professor asserted, with all the symbolic weight of his position behind him, that making childbirth free of charge would lead to more births. In Benin, a representative of a very important healthcare donor asserted that reductions in maternal mortality in northern countries had been achieved historically thanks to general medical practitioners. Although research evidence refutes these misconceived ideas, ${ }^{70}$ leading one of the authors to produce research notes for a non governmental organisation (NGO) ${ }^{40}$ and an edited book ${ }^{41}$ on these matters, no one dared to contradict those influential people during the deliberative dialogue. Making policy briefs available before or during the debates would have enabled participants to challenge these statements and given them research evidence to form their own conclusions. Lastly, healthcare is not the exclusive concern of the health ministry, and it is often difficult during these deliberative dialogues to invite and make enough room for other stakeholders, especially other ministries. In Niger, the presence of both the Ministry of Finance and the Ministry of Health allowed for a true debate, in which the two ministries' data concerning the enormous delays in reimbursements for free healthcare policies could be compared.

One thing we have learnt from our scoping review on deliberative dialogues is that not enough of them are being rigorously evaluated. ${ }^{18}$ As such, there is a real dearth of research evidence on the implementation and effectiveness of these opportunities for discussion, notably in Africa. It is therefore essential that organisers be able to prepare, to the extent possible, evaluations of their deliberative processes, particularly using mixed methods. Certain specific analytical frameworks may be of use. ${ }^{16}$ In Niger, for example, we were in a position to carry out participant observations during the deliberative dialogue, then in-depth interviews immediately afterwards, and again 12 months later, to better understand the outcomes and processes of the national conference. ${ }^{28}$ In Benin, we used a quantitative questionnaire based on the theory of planned behaviour ${ }^{42}$ to measure participants' intention to use the results of the deliberative dialogue. More than 100 participants were thus able to give their opinion on the usefulness of the findings and the changes they might produce.

\section{Limitations}

This article is the product of reflexive analysis, which is often desired but not very often actually practised in 
Box 2 Some suggestions for a successful national deliberative workshop

Plan the workshop in advance. This will allow to:

- make prior contact with high-level decision-makers.

- make the speakers' presentations clear and accessible (style and substance).

- prepare syntheses of the information in the form of briefs, in appropriate language and distributed (and, if possible, tested) in advance.

- inform the participants of what is expected of them during the workshop.

- Ensure the presence of a diversity of stakeholders concerned by the subject: decision-makers, researchers, implementers, communities, donors.

- Take account of the issues of power in the preparation, organisation and follow-up.

- Vary the types of data presented in the material sent out before the meeting and at the meeting using both tacit knowledge and research evidence.

- Allow time for deliberation, debate and discussion.

- Set up small working groups to delve deeper into certain subjects.

- Set up a follow-up committee for the recommendations and give it the means to function.

- Evaluate the processes and effects of the workshops with a view to improvement.

global health. ${ }^{27}$ As our participation in the first such workshop dates back to 2010, some memory bias may have crept into our reflection. We have attempted to mitigate any such bias by referring to the written documents prepared for all of those workshops. Individual interviews with all the actors would have allowed for more in-depth analysis, as we did in Niger ${ }^{28}$ and for a local workshop in Burkina Faso, ${ }^{19}$ but that was not the objective of this article, which presents a reflexive analysis. However, there is an urgent need for further studies on the organisation and effectiveness of deliberative dialogue in Africa, especially studies based on appropriate analytical frameworks or theories. Such studies could also, for example, consider the literature on group decision-making processes. ${ }^{43}{ }^{44}$ We hope the present article will open a window of opportunity in that direction.

\section{CONCLUSION}

In this paper we have attempted to explain the importance of taking into account the specific contexts in West Africa so as to increase the probability of deliberative dialogue being effective. Given that 'reflexivity aims to bring about transformations in practice', ${ }^{45}$ in box 2 we offer, from our experiences, some practical recommendations to guide those wishing to engage in such a process.

Acknowledgements The authors thank everyone who participated in and funded these deliberative dialogues as well as the reviewers. The authors also thank Isobel Hié, who translated the manuscript and Donna Riley for editing the last version.
Contributors VR and CD analysed the process and wrote the manuscript. Both authors read and approved the final manuscript.

Funding Part of this work was supported by the Canadian Institutes of Health Research (CIHR), which funded the programme (ROH-115213). VR holds a CIHRfunded Research Chair in Applied Public Health (CPP-137901).

Disclaimer The sponsors had no role in the writing of the paper or in the decision to submit the article for publication.

Competing interests The authors were paid as consultants for some of the workshops mentioned in this article.

Provenance and peer review Not commissioned; externally peer reviewed.

Data sharing statement No additional data are available.

Open Access This is an Open Access article distributed in accordance with the Creative Commons Attribution Non Commercial (CC BY-NC 4.0) license, which permits others to distribute, remix, adapt, build upon this work non-commercially, and license their derivative works on different terms, provided the original work is properly cited and the use is non-commercial. See: http://creativecommons.org/ licenses/by-nc/4.0/

(c) Article author(s) (or their employer(s) unless otherwise stated in the text of the article) 2017. All rights reserved. No commercial use is permitted unless otherwise expressly granted.

\section{REFERENCES}

1. Langer L, Tripney J, Gough D. The science of using science: researching the use of research evidence in decision-making. University of London, Social Science Research Unit, Evidence for Policy and Practice Information and Co-ordinating Centre, 2016.

2. Oliver K, Innvar S, Lorenc T, et al. A systematic review of barriers to and facilitators of the use of evidence by policymakers. BMC Health Serv Res 2014;14:2.

3. Weber M. Le savant et le politique. Paris: Plon 10/18, 1963.

4. Olivier de Sardan JP. Health fee exemptions: controversies and misunderstandings around a research programme. Researchers and the public debate. BMC Health Serv Res 2015;15 (Suppl 3) http:// bmchealthservres.biomedcentral.com/articles/

5. Nutley SM, Walter I, Davies HTO. Using evidence: how research can inform public services. Bristol: Policy Press, 2007.

6. Siron S, Dagenais C, Ridde V. What research tells us about knowledge transfer strategies to improve public health in low-income countries: a scoping review. Int $J$ Public Health 2015;60:849-63.

7. Brouwere Vde, Lerberghe Wvan. eds.Safe motherhood strategies: a review of the evidence. Antwerp, Belgium: ITGPress, 2001.

8. Moat KA, Lavis JN, Abelson J. How contexts and issues influence the use of policy-relevant research syntheses: a critical interpretive synthesis. Milbank Q 2013;91:604-48.

9. Ellen ME, Léon G, Bouchard G, et al. Barriers, facilitators and views about next steps to implementing supports for evidence-informed decision-making in health systems: a qualitative study. Implement Sci 2014;9:179.

10. Lysenko LV, Abrami PC, Bernard RM, et al. Educational research in educational practice: predictors of use. Lysenko 2014;37:1-26.

11. Tricco AC, Cardoso R, Thomas SM, et al. Barriers and facilitators to uptake of systematic reviews by policy makers and health care managers: a scoping review. Implement Sci 2016;11:4.

12. Dagenais C, Queuille L, Ridde V. Evaluation of a knowledge transfer strategy from a user fee exemption program for vulnerable populations in Burkina Faso. Glob Health Promot 2013;20(1 Suppl):70-9.

13. Dagenais C, McSween-Cadieux E, Somé P-A, et al. A knowledge brokering program in burkina faso (West Africa): reflections from our experience. Health Syst Reform 2016;2:367-72.

14. Nabyonga-Orem J, Dovlo D, Kwamie A, et al. Policy dialogue to improve health outcomes in low income countries: what are the issues and way forward? BMC Health Serv Res 2016;16 (Suppl 4):217.

15. Rajan D, Adam T, El Husseiny D, et al. Briefing note: policy dialogue: what it is and how it can contribute to evidence-informed decisionmaking. Geneva: WHO, 2015.

16. Boyko JA, Lavis JN, Abelson J, et al. Deliberative dialogues as a mechanism for knowledge translation and exchange in health systems decision-making. Soc Sci Med 2012;75:1938-45.

17. Lavis JN, Boyko JA, Oxman AD, et al. SUPPORT Tools for evidenceinformed health policymaking (STP) 14: organising and using policy 
dialogues to support evidence-informed policymaking. Health Res Policy Syst 2009;7(Suppl 1):S14.

18. Dossa R, Dogba J, Mandiangu N, et al. Implementation of deliberative dialogues to promote the use of evidence-based decisions in primary care: a scoping review. Quebec: NAPCRG Annual Meeting, 2017.

19. Mc Sween-Cadieux E, Dagenais C, Somé PA, et al. Research dissemination workshops: observations and implications based on an experience in Burkina Faso. Health Res Policy Syst 2017;15:43.

20. Ottersen T, Elovainio R, Evans DB, et al. Towards a coherent global framework for health financing: recommendations and recent developments. Health Econ Policy Law 2017;12:285-96.

21. Lavigne Delville P, Aghali A. A cheval donné, on ne regarde pas les dents. Les mécanismes et les impacts de l'aide vus par des praticiens nigériens. . Niamey, Niger: LASDEL/CRCHUM. Etudes et travaux numéro, 2010:83. 114.

22. Naudet J-D, Berg E. Organisation for economic co-operation and development, sahel club. Trouver des problèmes aux solutions vingt ans d'aide au sahel. Paris: Organisation de Coopération et de Développement Économiques, 1999.

23. Paul E, Sokegbe S, Kashala J-P, et al. Harmonisation et rationalisation du FBR en vue de sa pérennisation. Cotonou: Note de politique, 2017.

24. Gautier L, Ridde V. Health financing policies in sub-saharan Africa: government ownership or donors' influence? A scoping review of policymaking processes. Glob Health Res Policy 2017;2:23.

25. Sombié I, Aidam J, Konaté B, et al. The state of the research for health environment in the ministries of health of the Economic Community of the West African States (ECOWAS). Health Res Policy Syst 2013;11:35

26. Olivier de Sardan J-P. Promouvoir la recherche face à la consultance. Cah Détudes Afr 2011;202-203:511-28.

27. Tremblay MC, Parent AA. Reflexivity in PHIR: let's have a reflexive talk!. Can J Public Health 2014;105:221-3.

28. Moha M, Ridde V. La conférence nationale sur la gratuité des soins au Niger : des interactions nécessaires. In: Olivier de Sardan J-P, Ridde V, eds. Une politique publique de santé et ses contradictions. Gratuité soins au Burkina Faso au Mali au Niger. Paris: Khartala, 2014.

29. Ridde V. Per diems undermine health interventions, systems and research in Africa: burying our heads in the sand. Trop Med Int Health 2010;15:E1-E4.

30. Jaffrè Y. Les objectiff les séminaires et les recommandations permettent d'améliorer la santé des populations. In: Ridde V, Ouattara F, Les idées reçues en santé mondiale. Montréal, Rennes: Presses de l'Université de Montréal; Presses de l'École des Hautes Études en Santé Publiqu, 2015:225-9.
31. Moat KA, Lavis JN, Clancy SJ, et al. Evidence briefs and deliberative dialogues: perceptions and intentions to act on what was learnt. Bull World Health Organ 2014;92:20-8.

32. Ridde V, Faye A, Hane F, et al. La capitalisation du PAODESPAGOSAN: accompagnements pour les analyses, échanges sur le Forum et atelier de restitutions. Montreal, Canada: Unité de santé internationale (USI) École de santé publique de l'Université de Montréal (ESPUM); Coopération technique Belge, 2017:43.

33. Ridde V, Queuille L, Kafando Y, eds. Capitalisations de politiques publiques d'exemption du paiement des soins en Afrique de l'Ouest. Ouagadougou: CRCHUM/HELP/ECHO, 2012. http://www.vesa-tc. umontreal.ca/pdf/2012/livre_CAPI.pdf

34. Committee on the Science of Science Communication. Communicating science effectively: a research agenda. Washington: The National Academy Press, 2016.

35. Beynon P, Chapoy C, Gaarder M, et al. What difference does a policy brief make? Institute of Development Studies the International Initiative for Impact Evaluation, 2012:115

36. Neumann RK, Reed M. How to make a policy brief that has real impact: Fast Track Impact, 2015. http://www.fasttrackimpact.com/ single-post/2015/12/19/How-to-make-a-policy-brief-that-has-realimpact

37. Horton R, et al. Rapport final du groupe d'experts de la commission de haut niveau sur l'emploi en santé et la croissance économique. Geneva, Switzerland: Organisation mondiale de la Santé, 2016:72.

38. Bryson JM, Patton MQ, Bowman RA. Working with evaluation stakeholders: a rationale, step-wise approach and toolkit. Eval Program Plann 2011;34:1-12.

39. Brugha R, Varvasovszky Z. Stakeholder analysis: a review. Health Policy Plan 2000;15:239-46.

40. Ridde V, Queuille L, Ndour M. Nine misconceptions about free healthcare in sub-Saharan Africa. Dev Stud Res 2014;1:54-63.

41. Ridde V, Ouattara F. Des idées reçues en santé mondiale. Montréal, Rennes: Presses de l'Université de Montréal; Presses de l'École des Hautes Études en Santé Publique, 2015.

42. Ajzen I. The theory of planned behavior. Organ Behav Hum Decis Process 1991;50:179-211.

43. Nutt PC. Why decisions fail avoiding the blunders and traps that lead to debacles. San Francisco, Calif: Berrett-Koehler Publishers, 2002. (accessed 16 Sep 2017).

44. Franco LA, Rouwette EAJA, Korzilius H. Different paths to consensus? The impact of need for closure on model-supported group conflict management. Eur J Oper Res 2016:249:878-89.

45. Bisset S, Tremblay MC, Wright MT, et al. Can reflexivity be learned? An experience with tobacco control practitioners in Canada. Health Promot Int 2015:dav080. 